University of Wollongong

Research Online

Faculty of Social Sciences - Papers (Archive) Faculty of Arts, Social Sciences \& Humanities

$1-1-2017$

Significance and Novelty effects in single-trial ERP components and autonomic responses

Brett MacDonald

University of Wollongong, bm12@uowmail.edu.au

Robert J. Barry

University of Wollongong, rbarry@uow.edu.au

Follow this and additional works at: https://ro.uow.edu.au/sspapers

Part of the Education Commons, and the Social and Behavioral Sciences Commons

Research Online is the open access institutional repository for the University of Wollongong. For further information contact the UOW Library: research-pubs@uow.edu.au 


\title{
Significance and Novelty effects in single-trial ERP components and autonomic responses
}

\author{
Abstract \\ 2017 Elsevier B.V.The phasic orienting reflex (OR) was investigated in two counterbalanced blocks of an \\ auditory dishabituation paradigm differing in stimulus Significance (operationalised as tone counting). \\ Twelve tones were presented at very long, randomly-varying interstimulus intervals (ISIs). Novelty and \\ Significance were varied within subjects. Stimulus-response patterns were assessed to find ERP matches \\ for autonomic measures. The phasic OR index was represented by the skin conductance response (SCR). \\ SCR decremented over 10 standard trials, showed recovery on trial 11 (change trial), enhancement to re- \\ presentation of the standard tone (trial 12: dishabituation), and a main effect of Significance over the first \\ 10 trials $i$ demonstrating the formal criteria for an OR index. The evoked cardiac response (HR) \\ subcomponents ECR1 (deceleration) and ECR2 (acceleration) showed no trial effects, but ECR2 showed a \\ Significance effect. Respiratory pause (RP) decreased linearly over trials, and showed recovery, but no \\ dishabituation or Significance effect. Temporal PCA was applied to single-trial EOG-corrected data. Ten \\ ERP components were extracted: P1, N1-3, N1-1, PN, P2, P3a, P3b, HabP3, a Frontal Slow Wave (FSW), \\ and the Classic SW. The dependent measures showed 4 distinct patterns. Pattern 1: No trial or \\ Significance effects (ECR1, P1, N1-3, P3a, FSW); Pattern 2: No trial effect but a Significance effect (ECR2, \\ N1-1, P2); Pattern 3: Trial but not Significance effects (RP, PN, P3b, HabP3); Pattern 4: Both trial and \\ Significance effects (SCR and Classic SW). The evidenced fractionation of autonomic and central \\ measures is compatible with Preliminary Process Theory (PPT), contrary to the notion of a unitary OR.

\section{Disciplines} \\ Education | Social and Behavioral Sciences

\section{Publication Details} \\ MacDonald, B. \& Barry, R. (2017). Significance and Novelty effects in single-trial ERP components and \\ autonomic responses. International Journal of Psychophysiology, 117 48-64.
}


Significance and Novelty effects in single-trial ERP components and autonomic responses

\author{
Brett MacDonald*, Robert J. Barry
}

Centre for Psychophysics, Psychophysiology, and Psychopharmacology, Brain \& Behaviour Research Institute, and School of Psychology, University of Wollongong, Wollongong 2522, Australia

Note to type-setter: "Brain \& Behaviour Research Institute" is a registered name and should not be changed in any way.

*Corresponding author

Email: bm12@uowmail.edu.au

Phone: +61242214496

Fax: +61242214421

Keywords: Single-trial ERPs; Dishabituation paradigm; Skin Conductance Response; Orienting 
Reflex (OR); Principal Components Analysis; Significance 


\begin{abstract}
The phasic orienting reflex (OR) was investigated in two counterbalanced blocks of an auditory dishabituation paradigm differing in stimulus Significance (operationalised as tone counting). Twelve tones were presented at very long, randomly-varying interstimulus intervals (ISIs). Novelty and Significance were varied within subjects. Stimulus-response patterns were assessed to find ERP matches for autonomic measures. The phasic OR index was represented by the skin conductance response (SCR). SCR decremented over 10 standard trials, showed recovery on trial 11 (change trial), enhancement to re-presentation of the standard tone (trial 12: dishabituation), and a main effect of Significance over the first 10 trials - demonstrating the formal criteria for an OR index. The evoked cardiac response (HR) subcomponents ECR1 (deceleration) and ECR2 (acceleration) showed no trial effects, but ECR2 showed a Significance effect. Respiratory pause (RP) decreased linearly over trials, and showed recovery, but no dishabituation or Significance effect. Temporal PCA was applied to single-trial EOG-corrected data. Ten ERP components were extracted: P1, N1-3, N1-1, PN, P2, P3a, P3b, HabP3, a Frontal Slow Wave (FSW), and the Classic SW. The dependent measures showed 4 distinct patterns. Pattern 1: No trial or Significance effects (ECR1, P1, N1-3, P3a, FSW); Pattern 2: No trial effect but a Significance effect (ECR2, N1-1, P2); Pattern 3: Trial but not Significance effects (RP, PN, P3b, HabP3); Pattern 4: Both trial and Significance effects (SCR and Classic SW). The evidenced fractionation of autonomic and central measures is compatible with Preliminary Process Theory (PPT), contrary to the notion of a unitary OR.
\end{abstract}




\section{Introduction}

The slightest discernable stimulus change evokes an immediate response, the investigatory orienting reflex (OR), along with orientation toward the change (for a comprehensive overview see Sokolov, 1963a). The magnitude of the OR diminishes when the same stimulus is re-presented (Sokolov, 1963a,b), but if any perceived aspect of the stimulus is changed, the OR is reinstated (recovery) (Barry, 1996; O'Gorman et al., 1970). Recovery is followed by dishabituation (response enhancement for the re-presentation of the original stimulus; Barry and James, 1981a; Rankin et al., 2009; Thompson and Spencer, 1966). This hallmark OR pattern distinguishes true habituation from similar decrementing processes such as fatigue, refractoriness, and sensory adaptation (Budd et al., 1998). The OR is also susceptible to intensity variation in the moderate range (approx. 50 to $90 \mathrm{~dB}$ ), showing a direct proportionality to stimulus intensity (Barry, 1977a; Jackson, 1974; Sokolov, 1963b). This involuntary or reflexive OR is evoked solely by changes in physical aspects of the stimulus such as intensity. The SCR has proven to be the only reliable and consistent 'yardstick' of the involuntary OR, demonstrating the stimulus-response pattern required of the phasic OR: decrement (Barry, 1975, 1977a,b; Jackson, 1974; Edwards, 1974, 1975; MacDonald and Barry, 2014; MacDonald et al., 2015; O'Gorman et al., 1970; Raskin et al., 1969; Sokolov, 1963a,b), recovery on the change trial (Barry and James, 1981a; Edwards, 1975; MacDonald and Barry, 2014; MacDonald et al., 2015; O’Gorman et al., 1970; Sokolov, 1960, 1963b; Steiner and Barry, 2011, 2014; Zimny and Schwabe, 1966), and dishabituation to the re-presentation of the standard stimulus (Barry and James, 1981a; MacDonald and Barry, 2014; MacDonald et al., 2015; Steiner and Barry, 2011, 2014).

The voluntary OR is generated when the attributes of the stimulus change beyond the physical dimensions (Barry, 1984a, 1996), and the OR is enhanced. Instruction to count a series of stimuli silently and report the total imparts significance (Barry, 1984a,b,c, 2004; Lacey and Lacey, 1980; Maltzman, 1979, 1990; Sokolov, 1963a). Although counting may involve aspects 
of memory and the counting process, the general attentional effect is compatible with the original Sokolovian concept of significance, including the instruction to mentally count stimuli (Sokolov, 1963b). The ongoing process of counting stimuli and maintaining the count in memory represents cognitive load (e.g., Barry and Tremayne, 1987). Experimenter instructions induce a predisposing state (cortical set) that 'steers' attention to significant stimuli, resulting in the voluntary OR. Directed attention manifests in prestimulus vigilance and/or poststimulus signal value. Significant stimuli have shown a slightly higher initial OR (Barry, 2004; Ben-Shakhar, 1980; Maltzman, 1990), that remains larger over trials (Barry, 2004; Iacono and Lykken, 1983; Maltzman, 1990; Steiner and Barry, 2011, 2014), with a slower decrement to repetition (Barry, 2004; Ben-Shakhar, 1980; Iacono and Lykken, 1983, Maltzman, 1990).

\subsection{Response fractionation of the OR}

When an OR-linked determinant (e.g., novelty) is varied, different time-locked measures from various systems were initially believed to exhibit the same directional response change, demonstrating a "unitary system" (Sokolov, 1960, p. 191). Empirically these various measures should show covariation. The idea of a unitary OR has been contradicted by data from auditory (Barry, 1977a,b) and visual protocols (Barry and James, 1981a,b). Intensity and Significance were manipulated by Barry (1977a,b) in habituation paradigms. Measures associated closely to those used by Sokolov: SCR, heart rate (HR; unavailable to Sokolov), EEG alpha desynchronisation, cephalic vasodilation and peripheral vasoconstriction (PVC) (AC- rather than DC-coupled), and respiratory pause (RP), were dependent measures. Phasic responses from the various measures failed to covary; instead, different stimulus-response patterns emerged, demonstrating response fractionation with the stimulus parameters. Response decrement for stimulus repetition was observed for SCR, RP, and EEG alpha desychronisation. Both SCR and PVC were sensitive to intensity variation; also, SCR was augmented by stimulus Significance. The obligatory small, transient heart rate deceleration marked stimulus onset, while an additional HR acceleratory component was associated with the Significance of the stimulus. Only SCR 
reflected the differing aspects of the phasic OR index: habituation over trials, and systematic variation with stimulus intensity and Significance. Since separate measures demonstrated stimulus-response patterns different to the phasic SCR, they are likely associated with preprocessing aspects of the OR rather than representing the OR per se. These findings invalidate the concept of a unitary OR.

More recent studies have affirmed the stimulus-response patterning of these measures reported earlier (Barry and James, 1981a,b; Barry, 1982, 2009). Preliminary Process Theory (PPT) describes aspects of pre-processing and processing of stimulus parameters leading to and generating the $\mathrm{OR}$, and encompasses the fractionating stimulus-response patterns of the measures that were not compatible with the unitary concept of the OR. An above-threshold stimulus in the OR range (i.e., distinct from threshold or pain levels) receives initial processing regardless of its physical attributes, indexed by HR deceleration and cephalic vasodilation. Encoding of novelty is marked by respiratory pause and EEG alpha desynchronisation. Stimulus magnitude is processed in parallel to novelty; this energy-related parameter is reflected in peripheral vasoconstriction (PVC). The interaction of novelty and magnitude processing generates the involuntary phasic OR for indifferent stimuli, indexed by SCR. Significance, operationalised by different cortical sets, is potentially influential on all these modules of OR pre-processing. These cortical sets, in turn, are a result of the interaction of a subject's expectations and experimenter's instructions (Barry, 1984b, 1996). Figure 1 depicts the sequential and parallel processing in PPT, modulated by Maltzman's cortical set (Barry, 1984b, 1988; Maltzman, 1979, 1990). The processing units are reflected in the various measures enclosed in the dashed boxes. Table 1 is presented here to clarify the acronyms used.

Figure 1 and Table 1 about here

\subsection{ERPs in the OR context}

PPT, based primarily on autonomic measures, offers considerable explanatory capacity in OR research. The autonomic measures have shown reliable and consistent stimulus-response 
patterns across studies where novelty, intensity, and (to a lesser degree) Significance have been manipulated in habituation/dishabituation protocols. To ensure the elicitation of the OR rather than a defence reflex, simple stimuli in the moderate range of intensity and rise/fall times have been utilised. PPT has been generalised more recently to incorporate single-trial ERPs that align with the pre-OR and OR processing and covary with the already-established autonomic measures indexing those processes. Acknowledging the critical role of novelty in OR research, single-trial PCA-derived ERPs have been employed as central measures in long-ISI paradigms. These do not require within-subject averaging (Barry et al., 2008), allowing novelty-based responses to be captured over the first few trials - a substantial benefit of employing long to very long ISIs.

\subsubsection{Comparisons between measures}

Nieuwenhuis et al. (2011) states that a described difference between two experimental effects (e.g., significant vs. non-significant response decrement in two dependent variables) is insufficient to claim that those measures differ in a characteristic. Testing the statistical interaction between measures and the aspect of interest (e.g., measure $\times$ trial decrement) supports the observed difference. Following this approach, as used by MacDonald and Barry (2014; MacDonald et al., 2015), trial and Significance effects in the relevant measures will be statistically tested against the OR index - SCR.

\subsubsection{The LPC in the OR context}

In recent work from our laboratory utilising long-ISI single-trial ERPs, we have reported a sequence of late positive complex (LPC) subcomponents separated by temporal PCA, in order of increasing latency: P3a, P3b, Novelty P3/HabP3, and the Slow Wave (SW). These ERP subcomponents can be distinguished according to eliciting conditions, topography, and sensitivity to task demands (Barry et al., 2011, 2013; MacDonald and Barry, 2014; Sutton and Ruchkin, 1984). Interestingly, the P3a has shown no sensitivity to novelty (Barry et al., 2013; MacDonald and Barry, 2014, MacDonald et al., 2015; Rushby and Barry, 2009) but is sensitive to intensity (Barry et al., 2013; Rushby et al., 2005; Squires et al., 1975), while the Novelty 
P3/HabP3 has proven sensitive to novelty (Barry and Rushby, 2006; Barry et al., 2011; MacDonald and Barry, 2014; MacDonald et al., 2015; Rushby et al., 2005; Rushby and Barry, 2009; Steiner et al., 2014), but not intensity (MacDonald et al., 2015; Rushby et al., 2005).

1.2.3. Stimulus-response patterns of autonomic and central measures

In a simple novelty study, MacDonald and Barry (2014) varied novelty within subjects and examined the stimulus-response patterns of SCR, HR, RP and temporal PCA-derived ERPs. SCR served as the OR benchmark and the SCR pattern of decrement, recovery, and dishabituation confirmed the suitability of the paradigm for OR study. Three stimulus-response patterns were obtained - Pattern 1: no sensitivity to novelty (HR deceleration, P1, N1-3, N1-1, PN, P2, and P3a); Pattern 2: decrement over trials but no recovery (P3b and SW); and Pattern 3: sensitive to all aspects of novelty (SCR, RP, and HabP3). In a subsequent study, MacDonald et al. (2015), additionally varied stimulus intensity between subjects. The trials patterns in that study confirmed the insensitivity of HR deceleration, P1, PN, and P2 to changes in novelty, confirming Pattern 1 of MacDonald and Barry (2014). Na, N1-1 and P3a were found to reflect stimulus intensity, along with peripheral vasoconstriction. Novelty and intensity dependency were reflected in the SCR, RP, P3b, HabP3, IntP3, and SW. Over both studies SCR, RP, P3b, $\mathrm{HabP}$, and SW have demonstrated a firm association with novelty.

\subsection{The present study}

This study follows the recommendations of Barry et al. (2013) and builds on MacDonald and Barry (2014) and MacDonald et al. (2015) by systematically varying within-subjects novelty and Significance in a dishabituation paradigm. Both autonomic and central measures are compared when Significance is varied within-subjects, an additional variable added to the previous novelty manipulations. Temporal PCA-derived ERP components were sought to match and extend the autonomic measures already linked to preliminary and OR processing.

The very long ISIs are beyond the refractory periods of the ERPs examined (Woods et al., 1980) and permit full resolution of the responses for all the measures. The single-trial data 
alleviate the need for averaging, allowing the rapidly-decrementing response of ERPs to be 'captured' (Ritter et al., 1968; Roth, 1973). Significance was operationalised as covertly counting stimuli rather than a button press.

Within-subjects responses are more sensitive than between-subjects responses for detecting condition differences, due to less intrinsic error variance. Significance was operationalised as the counting of tones; the main effect of Significance will be examined as the difference between Count and No Count responses over the first 10 trials. We predict SCR will demonstrate the OR response pattern: response decrement to standard stimulus presentations over trials, response enhancement at the change stimulus, and an increase tore-presentation of the standard stimulus (dishabituation) (Barry and James, 1981a; MacDonald and Barry, 2014; MacDonald et al., 2015; Rushby et al., 2005; Steiner and Barry, 2011). The increased response to counted stimuli should be evident as a main effect of Significance over the first 10 trials (Barry, 1981, 1982, 1988, 2004; Barry and Rushby, 2006; Steiner and Barry, 2011). The general ECR, with no prepared motor response requirement, should be represented as a biphasic waveform (Barry, 1988; 1996; Lawrence and Barry, 2009, 2010). The initial phasic HR deceleration (ECR1) is an obligatory response to all stimuli and should show no systematic variation over trials (Barry, 1977b; 1982; 1984b,c; 1986; Barry and James, 1981a; Barry et al., 2011; MacDonald and Barry, 2014; MacDonald et al., 2015) or Significance main effect (Barry, 1977b, 1981, 1982; Lawrence and Barry, 2009). The cardiac response to a significant stimulus is largely acceleratory and is considered to reflect the obligatory ECR1 overlaid by a hypothetical ECR2. Because ECR2 cannot be seen separately from ECR1, it is estimated from the late acceleration. ECR2 should not decrement, but may show a slight increase over trials if cognitive load increases (Barry, 1984b,c, 1996), and should reflect increased Significance from counting (Barry, 1984b,c; Kaiser et al., 2001; Lawrence and Barry, 2009; 2010). A substantial respiratory pause should be evident for the first stimulus, show a linear decrement over trials (Barry, 1981, 1982; Barry and James, 1981a,b; Barry et al., 2013; MacDonald and Barry, 2014; MacDonald et 
al., 2015), demonstrate recovery at the change stimulus (Barry and James, 1981a; MacDonald and Barry, 2014; MacDonald et al., 2015), but no increased response for the dishabituation trial (Barry and James, 1981a; MacDonald and Barry, 2014; MacDonald et al., 2015). Respiratory responses for counted stimuli are not expected to be enhanced (Barry, 1977b, 1981, 1982).

ERPs relevant to the phasic preliminary and OR processing as depicted by PPT should fall within the $600 \mathrm{~ms}$ latency range used previously for the temporal PCA. The P1 should be observed clearly in the raw data, emerge as a PCA-derived component, and show no decrement (MacDonald and Barry, 2014; MacDonald et al., 2015; Rushby and Barry, 2009). No main effect of Significance is expected (Boutros and Belger, 1999; Courchesne et al., 1975; Picton and Hillyard, 1974; Rushby and Barry, 2009). The N1 is not expected to show a trials effect (Barry et al., 2011, 2013; Rushby and Barry, 2009; MacDonald and Barry, 2014; MacDonald et al., 2015) or a Significance effect (Lawrence and Barry, 2009; Näätänen, 1988) over the first 10 trials. The PN PCA-derivative exhibits a frontal topography with a narrow peak within the accepted PN latency range. Trial effects have been equivocal: decrement was found by Barry et al. (2011) but not by MacDonald and Barry (2014) or MacDonald et al. (2015). To our knowledge no investigations have varied novelty and Significance jointly to yield a PCA-derived PN, consequently there are no predictions in regard to trial effects and Significance. The P2 is not expected to decrement over trials at these very long ISIs (Crowley and Colrain, 2004; MacDonald and Barry, 2014; MacDonald et al., 2015; Romero and Polich, 1996; Rushby and Barry, 2009) and no increase in the Count condition is expected (Rushby and Barry, 2009; Becker and Shapiro, 1980; Crowley and Colrain, 2004; Squires et al., 1975).

In regard to the LPC subcomponents, the P3a should show no trials effects (Barry et al., 2011; MacDonald and Barry, 2014; MacDonald et al., 2015; Pritchard, 1981; Rushby and Barry, 2009; Steiner et al., 2014). At very long ISIs the P3a aligns more closely with physical parameters (MacDonald and Barry, 2014; MacDonald et al., 2015) than cognitive elements, consequently no Significance effect is expected. Our predictions for the posterior P3b are based 
on results from OR protocols that incorporate counting of repeated identical stimuli of a fixed number. Steiner et al. (2014), in an auditory dishabituation paradigm at long ISIs, found that counting enhanced the $\mathrm{P} 3 \mathrm{~b}$. In that study no motor response was required and the P3b was derived from temporal PCA. Simple manipulation of Significance in the OR context is not common. Trial decrement has been shown under similar conditions (Barry et al., 2011; MacDonald and Barry, 2014; MacDonald et al., 2015) but with no recovery (MacDonald and Barry, 2014; MacDonald et al., 2015; Steiner et al., 2014). The P3b response should thus diminish over trials with no recovery and be enhanced for counted stimuli. The PCA-derived HabP3 subcomponent has proved sensitive to the first presentation of a simple stimulus - the 'newness’ per se (Barry et al., 2011; MacDonald and Barry, 2014; MacDonald et al., 2015; Rushby and Barry, 2009). In habituation/dishabituation studies it has demonstrated a varied distribution. A parietally focused topography has been reported when intensity/Significance has been manipulated in conjunction with novelty (Barry et al., 2013; MacDonald et al., 2015; Rushby et al., 2005; Steiner et al., 2014), this contrasts to the frontally focused topography found when novelty alone was varied (Barry et al., 2016; MacDonald and Barry, 2014). Response decrement has been the defining feature of the HabP3 (Barry and Rushby, 2006; Barry et al., 2011; MacDonald and Barry, 2014; MacDonald et al., 2015; Rushby et al., 2005; Rushby and Barry, 2009; Steiner et al., 2014) but not Barry et al. (2013), along with some recovery (MacDonald and Barry, 2014; MacDonald et al., 2015; Rushby et al., 2005; Steiner et al., 2014), and possibly dishabituation (MacDonald and Barry, 2014; Rushby et al., 2005). The observations of trial decrement and response recovery suggests novelty processing, indicating that novelty per $s e$ is the prime eliciting determinant. An effect of Significance has also been reported (Steiner et al., 2014) at long ISIs but the stimulus-response pattern of SCR was not available to affirm the Significance effect. Consequently the HabP3 should show a trial decrement, possible recovery, but no main effect of Significance. The classic SW has been identified as the early component of the SNW/O wave; the later broader component displays a general negative distribution 
(Rohrbaugh et al., 1978, 1984; Zimmer and Demmel, 2000). The SW has shown similarities to P3b, such as task and probability dependency, and overlaps the P3b in raw data (Donchin et al., 1978; Rohrbaugh et al., 1978; Squires et al., 1975). The classic SW has been associated with the OR (Loveless and Sandford, 1974; Rohrbaugh et al., 1984; Zimmer and Demmel, 2000). Therefore the SW should show a trial effect (MacDonald and Barry, 2014; MacDonald et al., 2015; Rushby et al., 2005; Zimmer, 2006; Zimmer and Demmel, 2000; but not Barry et al., 2011, 2013), but no response recovery (MacDonald and Barry, 2014; MacDonald et al., 2015). Greater SW responses are expected for counted stimuli with some right hemisphere enhancement (MacDonald et al., 2015; Rohrbaugh et al., 1984; Zimmer and Demmel, 2000; Rushby et al., 2005).

The tonic measures of SCL and HRL have been included here to address the concern that some Significance effects may be attributed to non-specific state changes rather than stimulusrelated Significance per se (Barry, 1982; O'Gorman, 1979). SCL has been used as a traditional arousal measure (Barry, 1982, 2004; Barry and Sokolov, 1993), whereas HRL has been suggested as a more appropriate measure of preparatory prestimulus vigilance (Barry, 1996, 2006; Tremayne and Barry, 1990, 2001).

\section{Methods}

\subsection{Participants}

Thirty-two university students participated in an experimental session as one means of fulfilling a course requirement (ages $18-60$, mean 22.8 years; 25 female; 26 right-handed). The procedure was explained, after which written consent was obtained that was consistent with the joint South East Sydney and Illawarra Area Health Service/University of Wollongong Human Research Ethics Committee approved protocol, and in line with the Declaration of Helsinki (World Medical Organisation, 1996). A demographic and screening questionnaire was completed by all the participants, and only those with normal hearing were included. A history of 
psychiatric illness, seizures, or severe head injury was used to exclude participants, along with those currently taking psychoactive drugs.

\subsection{Procedure}

Participants in the study were seated comfortably in a dimly-lit, sound attenuated, airconditioned testing booth, and fitted with headphones. They were told that they would hear sounds occasionally over the headphones. For the Count condition participants were instructed to count silently all the tones and report the total number of tones at the end of the session. Those in the No Count condition were told they were not required to do anything but relax. All

participants were asked to focus their eyes on the monitor screen, at a distance of $1.5 \mathrm{~m}$, where a fixation cross was centred, try not to move or blink, and remain relaxed. An EOG calibration task involving a series of vertical, horizontal, and blink eye movements was undertaken before the presentation of tones for both blocks (Croft and Barry, 2000).

In order to examine novelty and Significance variation, auditory stimuli of $80 \mathrm{~dB}$ tones at 1000 and $1500 \mathrm{~Hz}$, with a duration of $50 \mathrm{~ms}$ (plus $15 \mathrm{~ms}$ rise/fall times) were presented at a randomly variable ISI of 50 - $70 \mathrm{~s}$. Novelty reduction was operationalised by trial repetition. Participants received 10 tones at one frequency (standard), a change trial at the other frequency, and the original tone was re-presented on trial 12. For each participant zero, 1, or 2 standard tones were then randomly added to reduce the participants' ability to communicate details of the tone sequence. The standard/change frequencies were counterbalanced between participants. Each randomly-assigned participant completed a series of two tasks (one in each of the two blocks): task 1 (No Count or Count) and task 2 (the other condition). The initial condition in task 1 was counterbalanced between participants.

\subsection{Physiological Recording}

Acquisition and storage of data was performed by a digital signal-processing hardware and software package from Associative Measurement (AMLAB II).

\subsubsection{Electrodermal activity}


Silver-silver chloride $(\mathrm{Ag} / \mathrm{AgCl})$ electrodes filled with electrode paste of $0.05 \mathrm{M} \mathrm{NaCl}$ in an inert ointment base were used to record skin conductance. These were placed on the distal volar surface of digits II and III of the non-dominant hand. A constant voltage of $0.5 \mathrm{~V}$ was applied to the electrode pair that formed the input circuit. The changing current that represented conductance was recorded using a DC amplifier. Skin conductance was sampled continuously at $512 \mathrm{~Hz}$ but only every eighth data point was recorded (at $64 \mathrm{~Hz}$ ) to save space; interpolation back to $512 \mathrm{~Hz}$ was executed in Neuroscan software (Compumedics, Version 4.3).

\subsubsection{Cardiac activity}

The recording of the electrocardiogram (EKG) utilised pre-jelled disposable $\mathrm{Ag} / \mathrm{AgCl}$ electrodes attached at mid-sternum and above the third rib on the left mid-axillary line. The signal was amplified $\times 10,000$, and sampled by a 16 bit A/D converter at $512 \mathrm{~Hz}$.

\subsubsection{Respiratory activity}

A piezoelectric respiration transducer mounted on a Velcro belt (Pneumotrace II, UFI) recorded the respiratory changes. Respiratory responses were sampled continuously at $64 \mathrm{~Hz}$.

\subsubsection{Electroencephalogram}

EEG activity was recorded from 19 scalp sites using tin electrodes in a cap, referenced to linked ears and grounded by a cap electrode located mid-way between Fpz and Fz. Vertical eye movement (VEOG) was recorded from tin cup electrodes placed $2 \mathrm{~cm}$ above and below the left eye. Tin cup electrodes positioned on the outer canthus of each eye recorded horizontal eye movement (HEOG). Impedance for cap electrodes was less than $5 \mathrm{k} \Omega$ and for EOG and reference electrodes was less than $3 \mathrm{k} \Omega$. Balance of reference impedances was carefully executed. Scalp potentials were amplified $\times 20,000$, and $\mathrm{EOG} \times 5,000$, with a bandpass down 3 $\mathrm{dB}$ at 0.01 and $30 \mathrm{~Hz}$, and digitised at a rate of $512 \mathrm{~Hz}$. The EEG data were EOG corrected using the RAAA EOG Correction Program (Croft and Barry, 2000; Croft et al., 2005).

\subsection{Data Extraction}

\subsubsection{SCR}


The raw SCR waveforms were segmented offline in $8 \mathrm{~s}$ epochs beginning at stimulus onset. Differences between the values found at response onset within the $1-3$ s post-stimulus interval (Barry, 1990) and the maximum value of the subsequent peak were collected for each participant and for each trial 1 - 12. Square-root transformation was applied to these data to reduce the skew typically associated with small SCRs (Barry and Sokolov, 1993).

\subsubsection{Evoked Cardiac Response}

A locally produced $\mathrm{R}$-wave peak detection program that computed the $\mathrm{R}-\mathrm{R}$ intervals in ms was employed to analyse EKG data. Cardiac activity was calculated in terms of mean values of HR for $0.5 \mathrm{~s}$ intervals relative to event onset (Velden and Wölk, 1987). Each epoch of data commenced $2 \mathrm{~s}$ before stimulus onset and ended $5 \mathrm{~s}$ after stimulus onset. The phasic ECR consists of two additive components, an initial deceleration (ECR1) common to all stimuli, and an acceleratory ECR2 to significant stimuli. The ECR2 is reflected in the increased acceleration in the Count compared to No Count conditions. HR deceleration (ECR1) was defined as the maximum decrease in HR in the time range $-.25-1.75 \mathrm{~s}$ relative to prestimulus HR over the 12 trials. The longer latency ECR2 was measured as the maximum increase in HR in the time range $2.25-4.75$ s over the 12 trials.

\subsubsection{Respiratory pause}

Respiratory pause represents a relative lengthening of the respiratory period poststimulus relative to the prestimulus period. Rather than being a cessation of breathing, the pause is observed as a transient alteration of the respiratory cycle. Phasic respiratory changes were quantified as the difference in time between the periods of the cycle containing the stimulus onset and the prestimulus cycle (inspiration-inspiration); this difference was divided by the duration of the prestimulus cycle and expressed as a percentage.

2.4.4. Skin Conductance Level (Non-specific arousal) and Heart Rate Level

The subject's skin conductance level was defined as the average of 511 data points between -1000 and $0 \mathrm{~ms}$. The skin conductance level for the Count and No Count conditions was 
calculated for each subject as an average across 12 trials. Heart rate level was similarly quantified for each subject as the average across trials of $2 \mathrm{HR}$ data points between -1000 and 0 ms.

\subsubsection{ERPs}

Neuroscan software was used offline to process the continuous raw EEG data for the 100 ms pre- to $1000 \mathrm{~ms}$ post-stimulus period. The baseline of the immediate $100 \mathrm{~ms}$ prestimulus to stimulus onset was employed for the ERP data.

\subsection{Statistical Analysis}

Single-trial EOG-corrected data were submitted to a temporal PCA in the time range of $100-600 \mathrm{~ms}$ from 19 scalp locations across 32 subjects to derive and identify ERP components/subcomponents. A total of 14,592 cases $(32$ subjects $\times 12$ trials $\times 2$ conditions $\times 19$ sites) were submitted to PCA decomposition utilising Dien's ERP PCA toolkit (v. 2.23; Dien, 2010) in Matlab. The temporal PCA employed the covariance matrix; the number of ERP components obtained equalled the number of variables/time points (358 points). Kaiser normalisation was employed and Varimax rotation was applied to all components to maintain orthogonality and facilitate interpretation. Virtual ERP component amplitudes were calculated from the product of factor loadings, factor scores, and standard deviations and these were used for subsequent analysis. The virtual amplitudes for each identified component were subjected to a separate analysis of variance (MANOVA). Nine central sites represented topography, and the coronal plane [left (F3, C3, P3), midline (Fz, Cz, Pz) and right (F4, C4, P4)] and sagittal plane [frontal (F3, Fz, F4), central (C3, Cz, C4) and parietal (P3, Pz, P4)] were the repeated-measures factors. Planned contrasts within the coronal plane compared the left (L) vs. right (R) hemispheres, along with the midline (M) vs. the mean of the left and right hemispheres. In addition, the contrasts within the sagittal plane, frontal $(\mathrm{F})$ vs. parietal $(\mathrm{P})$ regions, and central (C) region vs. the mean of the frontal and parietal regions, were also analysed. These orthogonal 
planned contrasts and their interactions provide optimal, non-redundant information on the topographic distribution of the amplitude of each component.

The pooled maximum amplitude for each ERP component across one of three medial regions (frontal, central or parietal regions) was used for the subsequent analysis. All autonomic measures (including HR deceleration and acceleration) and ERP component maxima were examined separately for response decrement and Significance. Repeated measures multivariate analysis of variance (MANOVA) was used to examine the autonomic and ERP measures with the factors Trials (for trials 1 to10) and Significance (No Count vs. Count). Within Trials, decrement was examined by a linear trend. Responses for the change trial (recovery: trial 11 vs. 10) were investigated in separate MANOVAs if significant decrement over trials was found. Likewise, responses for the re-presentation trial (dishabituation: trial 12 vs. 10) were only examined if recovery on the change trial proved significant. Also the within-subjects Significance effect over the first 10 trials was examined for a main effect. A within-subjects Significance effect from the OR perspective would be indicated by an increase in response magnitude for counted stimuli (Count) in comparison to indifferent stimuli (No Count). The analysis of the ECR over a $5 \mathrm{~s}$ epoch also included a Time factor with planned comparisons to examine the linear, quadratic, and cubic trends over Time that define ECR. ECR1 and ECR2 were analysed by separate repeated measures MANOVAs with the factors Trials $(1-10)$ and Significance (Count/No Count); only the linear trend was examined to assess decrement. To test state differences between the levels of Significance, 2 separate one-way MANOVAs for SCL and HRL were employed.

Since counterbalancing was employed, possible carry-over effects may occur, and this was tested by separate MANOVAs for trials (1 to 10), recovery (trial $11 \mathrm{vs.} 10$, and dishabituation (trial 12 vs. 10) for SCR. Both a between-subject factor Order (Count first/No Count first) representing order of presentation and the within-subject factor Significance 
(Count/No Count) were included in these analyses. Carry-over effects would be indicated by a significant main effect or interaction involving Order.

In accordance with Nieuwenhuis et al. (2011), differences between SCR and RP/ECR1/ECR2, along with SCR and the virtual ERP components, were examined with separate repeated measures MANOVAs using Z-scores for each subject's measures. In the case of ERPs, a subject's ERP Z-scores represented the maximum mean amplitudes at either the frontal, central, or parietal region for each component; these were used for the comparison analysis. The phasic SCR was expected to represent the benchmark OR pattern: decrement, recovery, and dishabituation, plus a Significance main effect over 10 trials. In order to capture the essence of the brief novelty influence, the measure comparison to SCR analysis is examined over the first 5 trials where decrement is expected to be most substantial (Barry, 2004; Barry and Rushby, 2006). If a difference was found between the measure and SCR in that pattern aspect for its initial analyses (e.g., no trial effect for ECR1 and trial effect for SCR), the difference in that pattern aspect was tested with a repeated-measure MANOVA for that measure and SCR, over the relevant trials. The measure $\times$ decrement/recovery/dishabituation and/or measure $\times$ Significance was examined to test the observed differences. A significant interaction confirmed the difference between the measure and SCR for the pattern aspect; and subsequent pattern testing was not required. A non-significant interaction was interpreted as indicating that aspect of the pattern failed to differ significantly from SCR, consequently the next aspect of the stimulusresponse pattern was tested. The polarity was reversed for negative ERP components to ensure decrement, recovery, and dishabituation, were tested appropriately.

Congruence Coefficients $\left(r_{c}\right)$ were calculated for the common PCA-derived components of the present study and those of MacDonald and Barry (2014) in the latency range from 0 to 500 ms. The Congruence Coefficient indicates the degree of similarity and stability across experimental conditions based on latency, rise/fall times, and response magnitude rather than topographical similarities (Barry et al., 2014). 
No Bonferroni-type adjustment to $\alpha$ was necessary (Tabachnick and Fidell, 1989) since all contrasts in any Manova were planned and the number of contrasts did not exceed the degrees of freedom for effect. Since single degree of freedom contrasts are unaffected by the violations of sphericity assumptions common in repeated-measures analyses of physiological data, Greenhouse-Geisser type correction was not necessary (O’Brien and Kaiser, 1985). All the reported tests have $(1,31)$ degrees of freedom. The effect sizes $\left(\right.$ partial $\eta_{\mathrm{p}}{ }^{2}$ ) are suitably indicated.

A large number of independent measures are reported, and that increases the frequency of Type 1 errors. For each measure the probability of Type 1 error is the same $(p=.05)$, so in 20 significant test results for a given measure, 1 false positive is likely to occur. The frequency of false positives in another independent measure would also be 1 in 20 . For both measures together, the frequency will be 2 false positives, or 2 in 40 ; i.e., the probability remains at 05 . Howell (1997) argues that the increased frequency of Type 1 errors is not appropriately “controlled" by alpha level adjustment.

\section{Results}

No major artifacts in the autonomic or EEG data rendered specific data unusable; consequently data from all subjects were analysed appropriately.

\subsection{SCR}

The mean phasic SCR trace showed an onset latency of approx. $1.9 \mathrm{~s}$ and peak latency of approx. $4.1 \mathrm{~s}$. Substantial response diminution over trials was apparent in a linear trend $(F=$ 100.45, $p<.001, \eta_{\mathrm{p}}^{2}=.764$ ), evident in Fig. 2 , but no interaction with Significance was found. The SCR recovered to the change stimulus $\left(11>10: F=14.24, p=.001, \eta_{\mathrm{p}}{ }^{2}=.315\right)$ and dishabituated to the re-presented original stimulus $\left(12>10: F=10.96, p=.002, \eta_{\mathrm{p}}{ }^{2}=.261\right)$. The 
main effect of Significance was apparent over the first 10 trials $\left(F=6.92, p=.013, \eta_{\mathrm{p}}{ }^{2}=.182\right)$.

See Table 2. In the additional analyses checking for counterbalancing effects, no significant main effects of Order or any interactions involving Order were found.

Figure 2 and Table 2 about here

\subsection{ECRs}

Fig.3A shows the ECRs (relative to pre-stimulus HR) for the No Count and Count conditions. Both conditions exhibit a brief simple cardiac deceleration, more prominent in the No Count responses (ECR1), with a peak latency of approximately .75 s. The No Count response returns toward baseline, while the Count response overshoots the baseline with an additional rapid cardiac acceleration. The overall response profiles over the entire time interval can be accounted for by a marginal linear trend $\left(F=3.60, p=.067, \eta_{\mathrm{p}}{ }^{2}=.104\right)$ and a cubic trend $(F=$ $\left.14.01, p=.001, \eta_{\mathrm{p}}{ }^{2}=.331\right)$. The difference between conditions was indicated by a Significance by Time interaction $\left(\mathrm{NC}\right.$ vs. $\mathrm{C} \times$ linear trend: $F=8.41, p=.007, \eta_{\mathrm{p}}{ }^{2}=.213$, seen as a linear divergence of the condition responses. Count responses were generally larger (i.e., more positive) than No Count $\left(F=5.98, p=.02, \eta_{\mathrm{p}}{ }^{2}=.162\right)$. Subsequent analysis over the first $2.25 \mathrm{~s}$ revealed a significant quadratic trend $\left(F=28.72, p<.001, \eta_{\mathrm{p}}{ }^{2}=.481\right)$ that did not differ between conditions, representing the ECR1 component. The ERC2 is also included in Fig. 3A, calculated as the difference between the Count and No Count responses. The ECR2 demonstrated no transient deceleration, but rapidly accelerated to reach peak latency approx. $3.75 \mathrm{~s}$ post-stimulus onset. Neither maximum HR deceleration (mean -1.39 BPM at .75 s) nor maximum acceleration (mean 1.82 BPM at $3.25 \mathrm{~s}$ ) displayed response decrement (Figs. 3B and C) or interacted with Significance. However the difference between Count and No Count (ECR2), in contrast to ECR1, was represented by a main effect of Significance over the first 10 trials $(F=8.00, p=$ $\left..008, \eta_{\mathrm{p}}{ }^{2}=.205\right)$ reflecting the additional acceleration to that in the No Count condition.

Comparison of both components and SCR for trials yielded significant Measure $\left(\right.$ ECR1/ECR2 vs. SCR) $\times$ Trial (linear trend over 1-5) interactions: $F=62.91, p<.001, \eta_{\mathrm{p}}{ }^{2}=$ 
.670 and $\left.F=73.44, p<.001, \eta_{\mathrm{p}}{ }^{2}=.703\right)$ respectively. The difference between ECR 1 and SCR for Significance was indicated by the Measure by Significance interaction (Measure (ECR1 vs. $\mathrm{SCR}) \times$ Significance $\left(\mathrm{NC}\right.$ vs. C) interaction: $\left.F=6.76, p=.014, \eta_{\mathrm{p}}{ }^{2}=.179\right)$. HR component effects are depicted in Table 2.

Figure 3 about here

\subsection{Respiratory Pause}

Respiratory pause decreased linearly over trials $\left(F=10.07, p=.003, \eta_{\mathrm{p}}{ }^{2}=.245\right)$, and demonstrated recovery $\left(F=5.38, p=.027, \eta_{\mathrm{p}}{ }^{2}=.148\right)$, but dishabituation failed to reach significance. No main effect of Significance or interaction with trials 1-10 was found. These results are depicted in Fig. 4. The lack of dishabituation in RP was tested against SCR over trials 10 and 12; the Measure (RP vs. SCR) $\times$ Trial (12 vs. 10) interaction was non-significant, indicating that RP and SCR did not differ on dishabituation. However these measures differed for Significance: Measure (RP vs. SCR) $\times$ Significance (NC vs. C) interaction: $F=4.96, p=$ $.033, \eta_{\mathrm{p}}{ }^{2}=.138$. Table 2 shows these results.

Figure 4 about here

\subsection{ERP components}

The distinct peaks of P1, N1, P2, P3, and SW are labelled in the raw EOG-corrected mean ERP data of Fig. 5.

Figure 5 about here

The first 11 factors from the PCA decomposition over the $-100-600 \mathrm{~ms}$ latency range each carried at least $2 \%$ of the variance and were examined, but one factor (Factor 8), a likely artefact of PCA processing at the end of the latency range, was excluded from analysis. The remaining ten components/subcomponents explained $87.1 \%$ of the variance and were tentatively identified with respect to their peak latencies and topography: Factor 1 - classic SW at $535 \mathrm{~ms}$ (32.8\% of total variance), Factor $2-\mathrm{P} 3 \mathrm{~b}$ at $296 \mathrm{~ms}(21.1 \%$ of total variance), Factor $3-\mathrm{P} 2$ at $215 \mathrm{~ms}$ (9.2\% of total variance), Factor $4-\mathrm{N} 1-1$ at $117 \mathrm{~ms}$ (6.8\% of total variance), Factor 5 - 
Processing Negativity (PN) at $162 \mathrm{~ms}(6.0 \%$ of total variance), Factor $6-\mathrm{N} 1-3$ at $80 \mathrm{~ms}(2.5 \%$ of total variance), Factor 7 - HabP3 at $369 \mathrm{~ms}(2.4 \%$ of total variance), Factor 9 - FSW at 410 ms (2.2\% of total variance), Factor $10-\mathrm{P} 1$ at $43 \mathrm{~ms}$ (2.1\% of total variance), and Factor $11-$ P3a at $252 \mathrm{~ms}(2.0 \%$ of total variance).

Virtual ERPs consisted of the sum of these 10 identified ERP components over conditions for the 12 trials. Fig. 5 shows the comparison of these virtual and the actual ERPs. The grand means of the virtual ERPs mirror those of the raw ERPs at the midline regions $\mathrm{Fz}, \mathrm{Cz}$, and Pz.

The rescaled factor loadings of the 10 identified components/subcomponents are presented in Fig. 6 over the time range. The grand mean headmap for each component is placed above each maximum point of the corresponding peak, together with the peak latencies. The topography of the ERP components/subcomponents over the relevant trials and the overall mean for each condition are displayed in Fig.7. Table 2 summarises the Trials, Recovery, Dishabituation, and Significance results for each measure. Differences between SCR and measures are statistically tested when a non-significant aspect of a measure differs from that aspect of SCR; these results are included along with the stimulus-response pattern assigned to each measure. Fig. 8 depicts the 10 PCA-derived component amplitudes (pooled at the maximal midline region [frontal, central, or parietal]) as a function of trials 1 to 12 for each condition.

Figures 6, 7, 8 about here

\subsubsection{P1 (Central positive maximum)}

The P1 amplitude was greatest over the central region $\left(\mathrm{C}>\mathrm{F} / \mathrm{P}: F=64.84, p<.001, \eta_{\mathrm{p}}{ }^{2}\right.$ $=.677)$, and midline activity was enhanced over the frontal region $(\mathrm{F}>\mathrm{P} \times \mathrm{M}>\mathrm{L} / \mathrm{R}: F=6.76, p$ $\left.=.014, \eta_{\mathrm{p}}{ }^{2}=.179\right)$. No Trial or Significance main effects emerged, and there was no interaction between these variables. The lack of decrement was confirmed by the comparison of P1 and SCR yielding a significant Measure $(\mathrm{P} 1$ vs. $\mathrm{SCR}) \times$ Trial (linear trend over $1-5)$ interaction: $F=$ $50.07, p<.001, \eta_{\mathrm{p}}{ }^{2}=.618$. The comparison between P1 and SCR to assess Significance found a 
significant Measure (P1 vs. $\mathrm{SCR}) \times$ Significance $(\mathrm{NC}$ vs. $\mathrm{C})$ interaction: $F=4.85, p=.035, \eta_{\mathrm{p}}{ }^{2}=$ .135 .

\subsubsection{N1-3 (Parietal negative maximum)}

The N1-3 had a parietal topography $\left(\mathrm{F}<\mathrm{P}: F=16.03, p<.001, \eta_{\mathrm{p}}{ }^{2}=.341\right)$ and midline reduction $\left(\mathrm{M}<\mathrm{L} / \mathrm{R}: F=21.45, p<.001, \eta_{\mathrm{p}}{ }^{2}=.409\right)$. The latter effect is greater in the parietal region $\left(\mathrm{F}<\mathrm{P} \times \mathrm{M}<\mathrm{L} / \mathrm{R}: F=13.50, p=.001, \eta_{\mathrm{p}}{ }^{2}=.303\right)$, with minimal negative activity at the $\operatorname{vertex}\left(\mathrm{C}>\mathrm{F} / \mathrm{P} \times \mathrm{M}<\mathrm{L} / \mathrm{R}: F=22.50, p<.001, \eta_{\mathrm{p}}{ }^{2}=.421\right)$. The difference in activity between the frontal and parietal regions was greater in the left hemisphere $(\mathrm{F}<\mathrm{P} \times \mathrm{L}>\mathrm{R}: F=9.98, p=$ $\left..004, \eta_{\mathrm{p}}{ }^{2}=.243\right)$. No trial or Significance main effect, or their interaction, was found. A significant Measure (N1-3 vs. SCR) $\times$ Trial (linear trend over 1-5) interaction: $F=53.10, p<$ $.001, \eta_{\mathrm{p}}{ }^{2}=.631$ confirmed these measures' difference in decrement. Also the difference in Significance was confirmed by a Measure (N1-3 vs. SCR) $\times$ Significance (NC vs. C) interaction: $F=8.83, p=.006, \eta_{\mathrm{p}}^{2}=.222$.

\subsubsection{N1-1 (Central negative maximum)}

Fig. 7 displays the N1-1 with a strong central focus $\left(\mathrm{C}>\mathrm{F} / \mathrm{P}: F=155.21, p<.001, \eta_{\mathrm{p}}{ }^{2}=\right.$ $.834)$ and a midline topography $\left(\mathrm{M}>\mathrm{L} / \mathrm{R}: F=120.71, p<.001, \eta_{\mathrm{p}}{ }^{2}=.796\right)$; these effects interacted, reflecting an enhanced amplitude at the vertex $(\mathrm{C}>\mathrm{F} / \mathrm{P} \times \mathrm{M}>\mathrm{L} / \mathrm{R}: F=81.26, p<$ $\left..001, \eta_{\mathrm{p}}{ }^{2}=.724\right)$. In addition, the midline activity was enhanced in the frontal region $(\mathrm{F}>\mathrm{P} \times \mathrm{M}$ $\left.>\mathrm{L} / \mathrm{R}: F=22.43, p<.001, \eta_{\mathrm{p}}{ }^{2}=.420\right)$, and the central enhancement was larger in the left than the right hemisphere $\left(\mathrm{C}>\mathrm{F} / \mathrm{P} \times \mathrm{L}>\mathrm{R}: F=5.79, p=.022, \eta_{\mathrm{p}}{ }^{2}=.157\right)$. No Trial or Significance main effect, or their interaction, was found over the first 10 trials. A significant Measure (N1-1 vs. SCR) $\times$ Trial (linear trend over 1-5) interaction: $F=70.40, p<.001, \eta_{\mathrm{p}}{ }^{2}=.694$ confirmed the difference between N1-1 and SCR over the first 5 trials. No significant Measure by Significance interaction was found.

3.4.4. PN (Frontal negative maximum) 
PN was shown to be frontally dominant $\left(\mathrm{F}>\mathrm{P}: F=5.13, p=.031, \eta_{\mathrm{p}}{ }^{2}=.142\right)$, especially over the midline $\left(\mathrm{F}>\mathrm{P} \times \mathrm{M}>\mathrm{L} / \mathrm{R}: F=15.04, p=.001, \eta_{\mathrm{p}}{ }^{2}=.327\right)$. The difference between the central and the mean of the frontal and parietal regions was greater in the left hemisphere $(\mathrm{C}>$ $\left.\mathrm{F} / \mathrm{P} \times \mathrm{L}>\mathrm{R}: F=11.11, p=.002, \eta_{\mathrm{p}}{ }^{2}=.264\right)$. The frontal pooled maximum amplitude decremented over trials $\left(F=5.33, p=.028, \eta_{\mathrm{p}}{ }^{2}=.147\right)$, however no effect of Significance was apparent, nor interaction with Trial. Recovery (trial 11 vs. 10) was not observed. Comparison of PN and SCR for recovery found a significant interaction: Measure $(\mathrm{PN}$ vs. SCR) $\times$ Trial (11 vs. 10): $\left.F=4.41, p=.044, \eta_{\mathrm{p}}{ }^{2}=.125\right)$. A significant Measure $(\mathrm{PN}$ vs. SCR $) \times$ Significance $(\mathrm{NC}$ vs. C) interaction: $F=4.97, p=.033, \eta_{\mathrm{p}}{ }^{2}=.138$ confirmed the difference between PN and SCR for Significance.

\subsubsection{P2 (Central positive maximum)}

$\mathrm{P} 2$ showed a fronto-central topography $\left(\mathrm{F}>\mathrm{P}: F=30.34, p<.001, \eta_{\mathrm{p}}{ }^{2}=.494 ; \mathrm{C}>\mathrm{F} / \mathrm{P}: F\right.$ $\left.=51.86, p<.001, \eta_{\mathrm{p}}{ }^{2}=.626\right)$ with strong midline activity $\left(\mathrm{M}>\mathrm{L} / \mathrm{R}: F=63.19, p<.001, \eta_{\mathrm{p}}{ }^{2}=\right.$ .670). These effects interacted to produce maximum positive activity at the vertex $(\mathrm{C}>\mathrm{F} / \mathrm{P} \times \mathrm{M}$ $\left.>\mathrm{L} / \mathrm{R}: F=66.61, p<.001, \eta_{\mathrm{p}}{ }^{2}=.682\right)$ and frontal midline regions $(\mathrm{F}>\mathrm{P} \times \mathrm{M}>\mathrm{L} / \mathrm{R}: F=5.11, p$ $=.031, \eta_{\mathrm{p}}{ }^{2}=.142$ ). In addition, responses were greater in the left hemisphere than the right hemisphere $\left(\mathrm{L}>\mathrm{R}: F=9.64, p=.004, \eta_{\mathrm{p}}{ }^{2}=.237\right.$, especially in the central region $(\mathrm{C}>\mathrm{F} / \mathrm{P} \times \mathrm{L}>$ $\left.\mathrm{R}: \mathrm{F}=6.56, p=.015, \eta_{\mathrm{p}}{ }^{2}=.175\right)$. The central activity failed to decrement over trials, however a Significance main effect was evident $\left(F=4.36, p=.045, \eta_{\mathrm{p}}{ }^{2}=.123\right)$ but there was no interaction with Trial. Comparison for P2 and SCR over trials yielded a significant Measure (P2 vs. SCR) $\times$ Trial (linear trend over 1-5) interaction: $F=55.52, p<.001, \eta_{\mathrm{p}}^{2}=.641$.

\subsubsection{P3a (Central positive maximum)}

$\mathrm{P} 3 \mathrm{a}$ was characterised by elevated central $\left(\mathrm{C}>\mathrm{F} / \mathrm{P}: F=16.76, p<.001, \eta_{\mathrm{p}}{ }^{2}=.351\right)$ and midline activity $\left(\mathrm{M}>\mathrm{L} / \mathrm{R}: F=10.61, p=.003, \eta_{\mathrm{p}}{ }^{2}=.255\right)$. These effects interacted to display maximum amplitude at the vertex $\left(\mathrm{C}>\mathrm{F} / \mathrm{P} \times \mathrm{M}>\mathrm{L} / \mathrm{R}: F=7.92, p=.008, \eta_{\mathrm{p}}{ }^{2}=.204\right)$. The midline activity was also enhanced in the frontal region $(\mathrm{F}>\mathrm{P} \times \mathrm{M}>\mathrm{L} / \mathrm{R}: F=35.23, p<.001$, 
$\left.\eta_{\mathrm{p}}{ }^{2}=.532\right)$. No central decrement was observed over the first 10 trials and no Significance main effect, or interaction with Trial, was found. P3a differed significantly from SCR over the first 5 trials: Measure $(\mathrm{P} 3 \mathrm{a}$ vs. $\mathrm{SCR}) \times$ Trial (linear trend over $1-5)$ interaction: $F=42.05, p<.001, \eta_{\mathrm{p}}{ }^{2}$ $=.576$. Comparison between P3a and SCR for Significance yielded a significant difference: Measure (P3a vs. SCR) $\times$ Significance (NC vs. C) interaction: $F=8.78, p=.006, \eta_{\mathrm{p}}{ }^{2}=.221$.

\subsection{7. $\mathrm{P} 3 \mathrm{~b}$ (Parietal positive maximum)}

P3b showed a typical parieto-central topography $\left(\mathrm{P}>\mathrm{F}: F=21.51, p<.001, \eta_{\mathrm{p}}{ }^{2}=.410\right.$; $\left.\mathrm{C}>\mathrm{F} / \mathrm{P}: F=13.50, p=.001, \eta_{\mathrm{p}}{ }^{2}=.303\right)$, and strong midline activity $(\mathrm{M}>\mathrm{L} / \mathrm{R}: F=79.36, p<$ $\left..001, \eta_{\mathrm{p}}{ }^{2}=.719\right)$. The latter effect was prominent in the parietal region $(\mathrm{P}>\mathrm{F} \times \mathrm{M}>\mathrm{L} / \mathrm{R}: F=$ $\left.35.23, p<.001, \eta_{\mathrm{p}}{ }^{2}=.532\right)$. Parietal responses decremented over trials $\left(F=9.36, p=.005, \eta_{\mathrm{p}}{ }^{2}=\right.$ .232) but no effect of Significance, or interaction with Trial, was observed. No significant recovery was found, see Figs. 7 and 8. Comparison of P3b and SCR for recovery found a significant Measure $(\mathrm{P} 3 \mathrm{~b}$ vs. $\mathrm{SCR}) \times$ Trial $(11$ vs. 10$)$ interaction: $F=15.23, p<.001, \eta_{\mathrm{p}}{ }^{2}=$ .329). P3b and SCR also differed on their responses to Significance: Measure (P3b vs. SCR) $\times$ Significance (NC vs. C) interaction: $F=4.70, p=.038, \eta_{\mathrm{p}}{ }^{2}=.132$.

\subsubsection{HabP3 (Frontal positive maximum)}

HabP3 showed a frontal topography $\left(\mathrm{F}>\mathrm{P}: F=5.07, p=.032, \eta_{\mathrm{p}}{ }^{2}=.141\right)$ with a central reduction $\left(\mathrm{C}<\mathrm{F} / \mathrm{P}: F=59.63, p<.001, \eta_{\mathrm{p}}{ }^{2}=.658\right)$, both these effects were greater for the No Count condition: Significance $(\mathrm{NC}>\mathrm{C}) \times$ Sagittal $(\mathrm{F}>\mathrm{P}): F=9.45, p=.004, \eta_{\mathrm{p}}{ }^{2}=.234$ and Significance $(\mathrm{NC}>\mathrm{C}) \times$ Sagittal $(\mathrm{C}>\mathrm{F} / \mathrm{P}): F=7.34, p=.011, \eta_{\mathrm{p}}{ }^{2}=.191$ respectively. A midline reduction was also evident $\left(\mathrm{M}<\mathrm{L} / \mathrm{R}: F=5.06, p=.032, \eta_{\mathrm{p}}{ }^{2}=.140\right)$. The central and midline reductions interacted to indicate minimal positive activity at the vertex $\mathrm{C}>\mathrm{F} / \mathrm{P} \times \mathrm{M}$ $\left.<\mathrm{L} / \mathrm{R}: F=34.54, p<.001, \eta_{\mathrm{p}}{ }^{2}=.527\right)$. Averaged frontal activity reduced over trials $(F=12.29, p$ $=.001, \eta_{\mathrm{p}}{ }^{2}=.284$ ), but no recovery (trial 11 vs. 10) was observed. Responses for the No Count condition were generally larger than for the Count condition $\left(F=4.71, p=.038, \eta_{\mathrm{p}}{ }^{2}=.132\right)$, in the opposite direction to expectations; no interaction of this effect with Trial was found. A 
significant difference was found when HabP3 and SCR were compared for the recovery: Measure $(\mathrm{HabP3}$ vs. $\mathrm{SCR}) \times$ Trial $(11$ vs. 10$\left.): F=9.68, p=.004, \eta_{\mathrm{p}}{ }^{2}=.238\right)$. A significant difference was also found when HabP3 and SCR were compared for Significance: Measure (HabP3 vs. SCR) $\times$ Significance (NC vs. C) interaction: $F=10.63, p=.003, \eta_{\mathrm{p}}{ }^{2}=.255$.

\subsubsection{FSW (Frontal negative maximum)}

Topographically, FSW was dominant in the frontal region ( $\mathrm{F}>\mathrm{P}: F=11.54, p=.002, \eta_{\mathrm{p}}{ }^{2}$ $=.271)$, and exhibited enhanced midline activity in the frontal region $(\mathrm{F}>\mathrm{P} \times \mathrm{M}>\mathrm{L} / \mathrm{R}: F=$ $6.18, p=.019, \eta_{\mathrm{p}}^{2}=.166$ ). A central reduction was greater in the right hemisphere than the left hemisphere $\left(\mathrm{C}<\mathrm{F} / \mathrm{P} \times \mathrm{L}<\mathrm{R}: F=6.34, p=.017, \eta_{\mathrm{p}}{ }^{2}=.169\right)$. The No Count condition showed a greater amplitude in the frontal region: Significance $(\mathrm{NC}>\mathrm{C}) \times$ Sagittal $(\mathrm{F}>\mathrm{P}): F=7.02, p=$ $.013, \eta_{\mathrm{p}}{ }^{2}=.185$, particularly in the midline region: Significance $(\mathrm{NC}>\mathrm{C}) \times$ Sagittal $(\mathrm{F}>\mathrm{P}) \times$ Lateral $\left(\mathrm{M}>\mathrm{L} / \mathrm{R}: F=4.86, p=.035, \eta_{\mathrm{p}}{ }^{2}=.136\right.$. Frontal activity failed to decrement, and no main effect of Significance or interaction with Trial was noted. The FSW was compared to SCR over the first 5 trials for decrement, and the difference proved significant: Measure (FSW vs. $\mathrm{SCR}) \times$ Trial (linear trend over 1-5) interaction: $F=86.31, p<.001, \eta_{\mathrm{p}}{ }^{2}=.736$. The comparison between FSW and SCR for Significance showed some difference: Measure (FSW vs. SCR) $\times$ Significance (NC vs. C): $F=3.36, p=.076, \eta_{\mathrm{p}}^{2}=.098$.

\subsubsection{Classic SW (Parietal positive maximum)}

SW exhibited the typical negative frontal and positive parietal topography with a central reduction $\left(\mathrm{F}<\mathrm{P}: F=114.13, p<.001, \eta_{\mathrm{p}}{ }^{2}=.786 ; \mathrm{C}<\mathrm{F} / \mathrm{P}: F=10.53, p=.003, \eta_{\mathrm{p}}{ }^{2}=.253\right)$. Midline activity was greatest over the parietal region $\left(\mathrm{F}<\mathrm{P} \times \mathrm{M}>\mathrm{L} / \mathrm{R}: F=19.88, p<.001, \eta_{\mathrm{p}}{ }^{2}\right.$ $=.391)$. Positive activity was greater over the right hemisphere than the left hemisphere $(\mathrm{L}<\mathrm{R}$ : $\left.F=7.71, p=.009, \eta_{\mathrm{p}}{ }^{2}=.199\right)$. Over trials $1-10$, positive activity diminished $(F=22.73, p<$ $\left..001, \eta_{\mathrm{p}}^{2}=.423\right)$, but recovery was not apparent. A Significance main effect emerged ( $F=4.68$, $\left.p=.038, \eta_{\mathrm{p}}{ }^{2}=.131\right)$, but no interaction with Trial was found. Comparison of Parietal SW and SCR for recovery (trial 11 vs. 10) yielded no significant difference. Subsequent examination of a 
difference between SW and SCR for dishabituation (trial 12 vs. 10) also found no significant difference.

3.5. Skin Conductance and Heart Rate Levels (arousal and vigilance)

SCL failed to differ between the conditions $\mathrm{NC}(\mathrm{M}=9.11, \mathrm{SD}=4.48 \mu \mathrm{S})$ and $\mathrm{C}(\mathrm{M}=$ 9.45, $\mathrm{SD}=4.83 \mu \mathrm{S}), F<1$, nor was a difference found for HRL between $\mathrm{NC}(\mathrm{M}=72.79, \mathrm{SD}=$ 7.92 $\mathrm{BPM})$ and $\mathrm{C}(\mathrm{M}=72.21, \mathrm{SD}=8.36 \mathrm{BPM}), F<1$.

3.6. Stimulus-response patterns of autonomic and ERP measures

Four stimulus-response patterns emerged based on the observed aspects of trial decrement and Significance for each autonomic and ERP measure. Inclusion of a measure into a pattern was also supported by the Nieuwenhuis et al. (2011) test when required. Pattern 1: no decrement or Significance effect, represented by ECR1, P1, N1-3, P3a, and FSW. Pattern 2: no decrement, but a Significance effect, represented by ECR2, N1-1, and P2. Pattern 3: decrement but no Significance effect, grouped the measures RP, PN, HabP3, and P3b. Pattern 4 embodies the major defining aspects of the OR, both decrement and Significance effects; this group contains SCR and SW.

\subsection{Temporal comparison of PCA-derived ERP components between studies}

Fig. 9 depicts the topographies of the common ERP components identified in the latency range between 0 and $500 \mathrm{~ms}$ of this study and MacDonald and Barry (2014). The Congruence Coefficient, $r_{c}$, provides a quantitative measure of component similarity to affirm the visual correspondence. Lorenzo-Seva and ten Berge (2006) suggested that $r_{c}$ from $.85-.94$ indicates "fair similarity" and $r_{c}>.95$ indicates "good similarity", i.e., the components can be considered equivalent. Fig. 9 reveals equivalence of the N1-1, PN, P2, P3b, and SW over the studies, while the HabP3 and P1 correspond closely.

Figure 9 about here

\section{Discussion}


Examination of the effects of novelty and Significance follows on logically from our two previous investigations, where MacDonald and Barry (2014) varied novelty alone, and MacDonald et al. (2015) varied novelty and intensity jointly. Since the paradigm structure is comparable to those studies, the present study serves as a replication of the previous studies in regard to novelty. The manipulation of Significance was operationalised here by a simple counting task. A within-subjects Significance effect was represented as an increased response for counting vs. non-counting over trials 1 to 10 .

\subsection{Autonomic Response Patterns}

The three defining aspects of OR habituation were demonstrated by SCR: decrement, recovery, and dishabituation; a main effect of Significance was also observed over the first 10 trials. These results are in accord with findings involving novelty from other rare auditory dishabituation studies (Barry, 1981, 1982, 2004; Steiner and Barry, 2011, 2014) and instructions to count (Steiner and Barry, 2014; Steiner et al., 2014). Therefore, the stimulus-response pattern of all the other measures can be compared to that of the exemplar of the phasic OR - SCR. Additional testing confirmed the absence of effects due to order of presentation (counted vs. not counted blocks) in the SCR data, indicating that we achieved an unbiased within-subject testing of Significance in this study.

The overall cardiac response was represented by both linear and cubic trends over time that described the biphasic waveform (brief deceleration followed by an extended cardiac acceleration). Further analysis over the first $2.25 \mathrm{~s}$ yielded a strong quadratic trend, confirming the presence of the cardiac deceleration ECR1. A Significance by Time interaction indicated that the HR increased more for the Count than the No Count condition over time in a linear fashion. Both the ECR1 and the subsequent acceleratory component failed to decrement, however only the acceleration demonstrated a Significance effect. Both ECR deceleratory and acceleratory components differed markedly from SCR in regard to trials, and ECR1 differed for Significance (Nieuwenhuis et al., 2011 test). The phasic ECR1 has consistently shown no trial effect (Barry, 
1977a,b; Barry et al., 2011; Barry and James, 1981a; MacDonald and Barry, 2014; MacDonald et al., 2015) and no Significance dependency (Barry, 1977a,b, 1982, Lawrence and Barry, 2009). Likewise, the overall later acceleratory component (ECR2) failed to diminish over trials, but interestingly, it apparently increased with trials; although not significant, this is directionally consistent with increasing processing load (Barry, 1996; Barry and Tremayne, 1987). ECR2 showed a substantial main effect of Significance; this cognitive load finding is consistent with previous reports (Barry, 1984b,c; Kaiser et al., 2001; Lawrence and Barry, 2009, 2010). These findings for HR deceleration support the notion of the ECR1 functioning according to PPT at an early stage of stimulus processing, pre-OR elicitation, i.e., marking the physical transient detection. The longer latency ECR2, on the other hand, appears to relate to cognitive processing, developing over trials and marking observable cognitive load variation.

Respiratory pause is not a commonly utilised measure in OR investigations, even though it has been shown to be susceptible to changes in novelty (Sokolov, 1963a). RP decrement was represented in a linear trend over trials, consistent with earlier accounts (Barry 1977a,b, 1981, 1982; Barry and James, 1981a,b; Barry et al., 2013; MacDonald and Barry, 2014; MacDonald et al., 2015). A clear recovery was also observed, establishing the selectivity of stimulus processing to novelty (MacDonald and Barry, 2014; MacDonald et al., 2015). Dishabituation was absent, yet no significant difference was found between RP and SCR; this is consonant with recent reports (MacDonald and Barry, 2014; MacDonald et al., 2015). No Significance effect was found here, compatible with expectations from early work (Barry 1977b, 1981, 1982). MacDonald and Barry (2014) compared RP with SCR with respect to all three aspects of habituation and reported no significant differences between this measure and SCR for recovery and dishabituation; MacDonald et al. (2015) found recovery and no difference between these measures for dishabituation. These dishabituation studies, including the present one, demonstrate a nonsignificant increase in RP response on the dishabituation trial. Dishabituation remains a possibility according to the Niewenhaus test, but this may be due to low statistical power or 
greater subject variability at the end of the experimental session (from tiredness or a loss of attentional focus) and needs further investigation. Considering RP's strong association with novelty per se in the absence of Significance sensitivity, RP appears to index processing of stimulus 'newness', intermediate between stimulus registration and OR generation. The RP is placed in Pattern 3 based on the clear trial effect in the absence of a Significance effect.

The autonomic measures generally confirmed previous results. Four stimulus-response patterns can be identified for these autonomic measures: 1 . No trial decrement and no Significance effect (ECR1); 2. No trial decrement but a Significance effect (ECR2); 3. Trial decrement but no Significance effect (RP); and 4. Trial decrement and Significance effect (SCR). These patterns provided the template for the ERPs examined.

\subsection{ERP Findings}

Temporal PCA between $-100 \mathrm{~ms}$ and $600 \mathrm{~ms}$ permitted identification and analysis of 10 ERP components based on polarity, topography, and latency. The components were labelled tentatively in temporal order: P1, N1-3, N1-1, PN, P2, P3a, P3b, HabP3, FSW, and classic SW. Importantly, the common LPC subcomponents were arranged in the same temporal order consistently reported in recent OR investigations: P3a, P3b, 'Novelty P3'/HabP3, and classic SW (Barry et al., 2009; Barry et al., 2011; Barry et al., 2013; MacDonald and Barry, 2014; MacDonald et al., 2015; Rushby et al., 2005; Steiner et al., 2014). To our knowledge the PCAderived FSW has not been identified previously in dishabituation studies but the latency of this component places it before the classic SW; this needs further investigation in future studies.

The P1 has exhibited a fronto-central topography (Beer and Röder, 2004 - right ear reference; MacDonald and Barry, 2014; Rushby and Barry, 2009). Temporal PCA-derived P1 has failed to demonstrate a trial effect (MacDonald and Barry, 2014; MacDonald et al., 2015). No trial effects were expected (Gillette et al., 1997; Pratt, et al., 2008) and no Significance sensitivity was predicted. The P1 here showed a central distribution dominant frontally in accord with previous reports; no decrement or main effect of Significance over the first 10 trials was 
evident. When P1 was compared to SCR for trial and Significance both comparisons proved significant. Placement of the P1 in Pattern 1 was based on no observable trial or Significance effect.

The N1-3 in the present study exhibited a parietal topography. Trials and Significance effects were not observed. This component has been identified as a PCA-derived component in a number of studies (Barry et al., 2011; MacDonald and Barry, 2014). Barry et al. (2011), in a unique monaural auditory habituation study, examined horizontal eye movement toward the ear of stimulation as a measure of behavioural orienting, and SCR served as the phasic physiological OR index. The topography of the N1-3 was similar but more anterior to the present N1-3; the latency in that study was $77 \mathrm{~ms}$, compared to $80 \mathrm{~ms}$ in the present study. The N1-3 found in MacDonald and Barry (2014) showed a parieto-central topography similar to that found here, but with a latency of $94 \mathrm{~ms}$. In both these previous studies the N1-3 was elicited prior to the N1-1 and demonstrated no decrement, consistent with the findings here. Näätänen and Picton (1987) had described this component as displaying a vertex topography, but more parietal and widespread than the N1-1. Their functional significance was linked to an alerting capacity of sensory association after quiescence. Future investigations in OR-type paradigms may provide greater insight into this component. The lack of decrement and insensitivity to Significance warrants the inclusion of N1-3 into Pattern 1.

The composite N1 can be characterised by a vertex dominance (Vaughan and Ritter, 1970; Rushby and Barry, 2009; Barry et al., 2013; Squires et al., 1975), and is echoed in the PCA-derived counterpart (Rushby and Barry, 2009; Barry et al., 2013; MacDonald and Barry, 2014; MacDonald et al., 2015; Squires et al., 1975). The N1 has been reported as novelty independent at long ISIs (Barry et al., 2011; Barry et al., 2013; Rushby and Barry, 2009). The first “frontocental” component identified by Näätänen and Picton (1987, p. 386) reflects closely the composite N1 in regard to topography and associations to eliciting conditions (Näätänen and Picton, 1987). Both the composite N1 and the N1-1 component appear more reliant on the 
physical aspects of the stimulus than subsequent processing (Näätänen and Picton, 1987). In three studies (MacDonald and Barry, 2014; MacDonald et al., 2015; Barry et al., 2011) the identified N1-1 subcomponent showed a vertex topography; but was clearly insensitive to novelty. There are few studies examining Significance for the N1-1. Rushby and Barry (2009), in a dishabituation protocol at very long ISIs, found no effect of instruction, but this did not involve a counting task. Consequently, no effect of trial or Significance was predicted here. Our N1-1 displayed a vertex distribution and no significant trial effect; also a main effect of Significance failed to reach significance. Comparison of N1-1 to SCR for decrement over the first 5 trials revealed a significant difference, yet these measures did not differ significantly on the Significance test; consequently the possibility of N1-1 having some Significance dependency remains open. Fig. 8 indicates that counted stimuli had a larger response than non-counted stimuli, however a sizeable variability appears to overshadow this difference. Since N1-1 decrement was not evident and the Significance effect failed to differ from that of the SCR, these results led to the N1-1 tentatively being included in Pattern 2. This placement needs further consideration in future work.

The PN is typified by a frontal and midline distribution (Näätänen, 1982). The temporal PCA-derivative presents the same topography in the OR context (Barry et al., 2011; MacDonald and Barry, 2014; MacDonald et al., 2015). In the Introduction PN was shown to have exhibited variable patterns over stimulus repetition, and the present findings add to those of previous studies suggesting the PN represents an early reflexive attention-switching process. In this study the frontally-dominant PN demonstrated a trial but not Significance effect. Thus the PN was tentatively assigned to Pattern 3.

The PCA-derived P2 component has previously shown a strong central topography (MacDonald and Barry, 2014; MacDonald et al., 2015) and resistance to decrement (Crowley and Colrain, 2004; MacDonald and Barry, 2014; MacDonald et al., 2015; Rushby and Barry, 2009). No trial or Significance effect was anticipated. The P2 component in this study showed a 
fronto-central topography consistent with recent reports (MacDonald and Barry, 2104;

MacDonald et al., 2015). Interestingly, the response increased non-significantly over trials, consonant with MacDonald and Barry (2014), and with MacDonald et al. (2015) where the increase was significant. A main effect of Significance over the first 10 trials was clearly evident. The Significance effect for the P2 was not predicted and literature provides no clear foundation for this observation, especially when arousal is discounted. The absence of a decrementing trial effect and presence of a Significance effect places P2 in Pattern 2.

The P3a has consistently exhibited a central distribution (Barry et al., 2011; Rushby and Barry, 2009; MacDonald and Barry, 2014; MacDonald et al., 2015; Rushby et al., 2005; Squires et al., 1975). Rushby et al. (2005) found the PCA-derived P3a to decrement over trials at long ISIs, but trial effects have been conspicuously absent at very long ISIs (Rushby and Barry, 2009; Barry et al., 2011; MacDonald and Barry, 2014; MacDonald et al., 2015). Although there are some reports of Significance sensitivity (Rushby and Barry, 2009; Steiner et al., 2014), no trial or Significance effect was predicted; both these expectations were confirmed, and hence P3a was assigned to Pattern 1.

The parieto-central P3b has emerged as a conspicuous PCA-derived component in OR studies (Barry et al., 2013; MacDonald and Barry, 2014; MacDonald et al., 2015; Rushby and Barry, 2009; Rushby et al., 2005). Our parieto-central P3b showed decrement but no recovery, confirming predictions. We also predicted a Significance effect, but this was not evident and quite surprising. Both Figs.7 and 8 depict an initial difference in Significance that remains over the first two trials. It is possible that after some initial processing the greater proportion of the cognitive load related to counting was treated at a later stage, perhaps reflected in the SW. The finding of a decrement in the absence of a Significance effect warrants the P3b inclusion in Pattern 3.

In recent times, our laboratory has sought the novelty ERP response in single-trial data. While the decrement over trials in the HabP3 has been consistently found, the response to 
Significance variation has received scant attention. We expected the characteristic decrement with a possible recovery, but a Significance effect was not predicted. The frontal HabP3 found here matched the HabP3 of MacDonald and Barry (2014) for topography and decrement, but not recovery (a suggestion of frontal recovery can be seen in Fig. 7). No Significance effect emerged, as predicted. Comparisons with SCR for recovery and Significance both proved significantly different. Since the HabP3 showed decrement but no Significance effect, the HabP3 was grouped in Pattern 3.

The FSW was an unexpected discovery in the latency range between the HabP3 and SW. The latency of $410 \mathrm{~ms}$ places it at the beginning of the broad SW yet it has a topography different to the later classic SW. The FSW matches neither of the O-wave components in regard to topography or latency (Loveless and Sandford, 1974; Rohrbaugh et al., 1984; Zimmer and Demmel, 2000). The FSW in this study exhibited a frontal midline topography that failed to decrement. The No Count responses were greater than Count. SWs have shown some enhancement to novelty and Significance (e.g. Rohrbaugh et al., 1978) but this FSW has shown neither. The validity of this component requires support from further investigations under similar conditions using PCA. The lack of a trial or Significance effect places this component in Pattern 1.

The frontally-negative and parietally-positive classic SW has been regularly reported from our laboratory in recent OR investigations utilising temporal PCA (Barry et al., 2011; Barry et al., 2013; MacDonald and Barry, 2014; MacDonald et al., 2015; Rushby et al., 2005). Such a SW occurring near the end of an epoch may simply be an outcome of the autocorrelation of EEG time-series data (Kayser and Tenke, 2003), but this component with similar topography has been reported at similar latencies over $150 \mathrm{~ms}$ before the end of longer PCA epochs (Rushby et al., 2005; Barry et al., 2011). Generally, the SW, in raw data and as a temporal PCA component, has demonstrated decrement as a main effect or a topographic interaction (Barry et al., 2011; MacDonald and Barry, 2014; MacDonald et al., 2015; Rushby et al., 2005; Zimmer and 
Demmel, 2000), with no recovery (MacDonald and Barry, 2014; MacDonald et al., 2015). Accordingly, decrement in the absence of recovery, and some effect of Significance, were predicted. Our PCA-derived SW demonstrated the decrement over trials as expected and no recovery. However, comparison of the SCR and SW indicated no difference for recovery or dishabituation, so neither recovery nor dishabituation can be definitively ruled out. The classic SW showed a main effect for Significance and also enhancement in the right hemisphere as predicted. Right hemisphere dominance has been linked to the orienting response (Maltzman, 1979; Rohrbaugh et al., 1984; Zimmer and Demmel, 2000). The classic SW has been included in Pattern 4 based on decrement and Significance effects.

Both SCL and HRL were examined to address the possibility that Significance effects were produced by state changes. No significant state differences between conditions were found across trials 1-12. Therefore non-specific arousal, as indexed by SCL, did not produce the Significance effects in this study, nor was there any evidence of prestimulus vigilance differences suggested by HRL. Hence the enhanced responses associated with counting can be solely and directly attributed to Significance.

\subsection{ERP Component Patterns}

The ERP components/subcomponents and autonomic measures have been grouped provisionally into 4 patterns. Stimulus-response patterns were used to decide on each measure's inclusion in a pattern. Pattern 1 is characterised by insensitivity to both novelty and Significance: ECR1, P1, N1-3, P3a, and FSW. The independence from novelty has grouped ECR1, P1, and N1-3 together across three studies (here and MacDonald and Barry, 2014; MacDonald et al., 2015); but note N1-3 was not found in MacDonald and Barry (2014). The clustering of these measures in Pattern 1 supports the notion of an early stage of stimulus processing in the OR context, based on the variation of physical parameters, akin to transient detection.

Pattern 2 measures show no decrement over trials, but sensitivity to stimulus Significance: ECR2, N1-1, and P2. ECR2 has been linked previously to cognitive load 
(Lawrence and Barry, 2009, 2010) and the P3a has shown some sensitivity to executive processing (Rushby and Barry, 2009; Steiner et al., 2014). The Significance effect found for P2 was not anticipated, therefore inclusion of $\mathrm{P} 2$ in this pattern is tentative.

Pattern 3 measures demonstrate novelty but not Significance sensitivity: RP, PN, P3b, HabP3. These four measures have generally been reported as decrementing in OR-type paradigms where the same simple auditory stimulus was re-presented. In regard to the PN, although decrement has been observed, MacDonald et al. (2015) described a non-significant increase. Further comparable OR research using SCR as the OR benchmark is needed to confirm this pivotal aspect of habituation for the PN and address the paucity of these studies in the literature.

Pattern 4 is defined by the OR determinants of novelty and Significance, and inclusions in this pattern are: SCR and classic SW. Both the SCR and classic SW have close relationships to the phasic OR in previous literature.

The number of patterns equalled the combinations of novelty and Significance, and a separate autonomic measure was found to group into each of the four patterns. This configuration is consistent with the modules of processing proposed in PPT and the notion that autonomic measures serving as their indices have matching ERP counterparts.

Congruence coefficients confirmed the between-studies similarity and stability of the matched PCA-derived ERP components. Inspection of the topographies in Fig.9 also reveals close matches of the component pairs, and the latency order of the LPC subcomponents has been preserved: P3a, P3b, HabP3, and classic SW. Together these indicate stable ERP components in the OR in these two dishabituation studies.

\section{Conclusion}

We have extended the examination of the OR determinants investigated by MacDonald and Barry (2014) and MacDonald et al. (2015) by varying novelty and Significance jointly. SCR 
showed all the defining aspects of the phasic OR examined here and was used as the OR 'yardstick' to assess each measure in relation to the OR. Tonic SCL and HRL data addressed the possible effects of arousal and vigilance. No differences in these tonic measures over conditions were found, demonstrating that the Significance effects found here can be attributed directly to the Significance manipulation alone. The emergent four stimulus-response patterns were based on the defining aspects of OR habituation and Significance. Once again ECR1 has shown the critical aspects of early stimulus processing and four ERPs emerge as possible central matches, thus furthering the development of PPT. Novelty sensitivity was demonstrated by RP, PN, P3b, HabP3, and the classic SW. Significance effects were found in ECR2, P2, and classic SW. The lack of a Significance effect in the P3b and the possibility of that effect in N1-1 were both surprising results that require confirmation by replication, along with the anomalous Significance effect for P2.

The response pattern of the classic SW in this study and in MacDonald and Barry (2014) and MacDonald et al. (2015) presents this LPC subcomponent as the most likely candidate for the central index of the phasic OR, consistent with early SW research. Importantly, the latency order of the LPC subcomponents has again been confirmed in the OR context, affirming the often disputed differentiation of the P3a and HabP3. These derived stimulus-response patterns contribute significantly to the ongoing development of PPT by introducing possible central matches for the autonomic measures, pending confirmatory findings. The present study has again found clear evidence of phasic measure fractionation, contrary to the unitary OR concept. The stimulus-response patterns identified confirm the patterns found in previous autonomic studies and strengthens the sequential and parallel-processing model of the OR proposed in PPT. Inclusion of blood pressure as another cardiac measure in future OR investigations would further consolidate the understanding of PPT. 


\section{References}

Althen, H., Grim, S., Escera, C., 2011. Fast Detection of Unexpected Sound Intensity

Decrements as Revealed by Human Evoked Potentials. Plos ONE 6(12):e28522.

Doi;10.1371/journal.pone.0028522.

Barry, R.J., 1975. Low -intensity auditory stimulation and the GSR orienting response. Physiol.

Psychol. 3, 98-100.

Barry, R.J., 1977a. Failure to find evidence of the unitary OR concept with indifferent lowintensity auditory stimuli. Physiol. Psychol. 5, 89-96.

Barry, R.J., 1977b. The effect of "significance" upon indices of Sokolov's orienting response: A new conceptualisation to replace the OR. Physiol. Psychol. 5, 209-214.

Barry, R.J., 1981. Signal Value and Preliminary Processes in OR Elicitation. Pav. J. Bio. Sci. 16, 144-150.

Barry, R.J., 1982. Novelty and Significance Effects in the Fractionation of Phasic OR Measures: A Synthesis with Traditional OR Theory. Psychophysiology 19, 28-35.

Barry, R.J., 1984a. The evoked cardiac response under processing load. Physiol. Psychol. 12, 3540.

Barry, R.J., 1984b. Preliminary Processes in O-R Elicitation. Acta Psychol. 55, 109-142.

Barry, R.J., 1984c. Trial effects in the evoked cardiac response under processing load. Physiol. Psychol. 12, 315-318.

Barry, R.J., 1986. Heart rate deceleration to innocuous stimuli: An index of the orienting response or stimulus registration. Physiol. Psychol. 14, 42-48.

Barry, R.J., 1988. Significance and components of the orienting response: effects of signal value versus vigilance. Int. J. Psychophysiol. 6, 343-346.

Barry, R.J., 1990. Scoring criteria for response latency and habituation in electrodermal research: a study in the context of the Orienting Response. Psychophysiology 27, 94-100.

Barry, R.J., 1996. Preliminary process theory: Towards an integrated account of the 
psychophysiology of cognitive processes. Acta Neurobiol. Exp. (War), 56, 469-484.

Barry, R.J., 2004. Stimulus Significance Effects in Habituation of the Phasic and Tonic

Orienting Reflex. Integ. Physiol. Behav. Sci. 39, 166-179.

Barry, R.J., 2006. Promise versus reality in relation to the unitary orienting reflex: A case study examining the role of theory in psychophysiology. Int. J. Psychophysiol. 62, 353-366.

Barry, R.J., 2009. Habituation of the Orienting Reflex and the development of Preliminary Process Theory. Neurobiol. Learn. Mem. 92, 235-242.

Barry, R.J., James, A.L., 1981a. Fractionation of phasic responses in a dishabituation paradigm. Physiol. Behav. 26, 69-75.

Barry, R.J., James, A.L., 1981b. Fractionation of respiratory and vascular responses with simple visual stimulation. Physio. Psychol. 9, 96-101.

Barry, R.J., Rushby, J.A., 2006. An orienting reflex perspective on anteriorisation of the P3 of the event-related potential. Exp. Brain. Res. 173, 539-545.

Barry, R.J., Sokolov, E.N., 1993. Habituation of phasic and tonic components of the orienting reflex. Int. J. Psychophysiol. 15, 39-42.

Barry, R.J., Tremayne, P., 1987. Separation of components in the evoked cardiac response under processing load. J. Psychophysiol. 1, 259-264.

Barry, R.J., Clarke, A.R., Johnson, S.J., Rushby, J.A., 2008. Timing of caffeine's impact on autonomic and central nervous system measures: clarification of arousal effects. Bio. Psychol. 77, 304-316.

Barry, R.J., De Blasio, F.M., Borchard, J.P., 2014. Sequential processing in the equiprobable auditory Go/NoGo task: Children vs. adults. Clin. Neurophysiol. 125, 1995-2006.

Barry, R.J., MacDonald., B., De Blasio, F.M., Steiner, G.Z., 2013. Linking components of eventrelated potentials and autonomic measures of the orienting reflex. Int. J. Psychophysiol. 89, 366-373.

Barry, R.J., MacDonald, B., Rushby, J.A., 2011. Single-trial event-related potentials and the 
orienting reflex to monaural tones. Int. J. Psychophysiol. 79, 127-136.

Barry, R.J., Steiner, G., De Blasio, F,M., 2016. Reinstating the Novelty P3. Sci. Rep. 6, 31200; doi: $10.1038 /$ srep31200.

Becker, D.E., Shapiro, D., 1980. Directing Attention Toward Stimuli Affects the P300 But Not the Orienting Response. Psychophysiology 17 385-389.

Ben-Shakhar, G., 1980. Habituation of the Orienting Response to Complex Sequences of Stimuli. Psychophysiology 17, 524-534.

Beer, A.L., Röder, B., 2004. Attention to motion enhances processing of both visual and auditory stimuli: an event-related potential study. Cog. Brain. Res. 18, 205-225.

Boutros, N.N., Belger, A., 1999. Midlatency evoked potential attenuation and augmentation reflect different aspects of sensory gating. Bio. Psychiatry. 45, 917-922.

Budd, T.W., Barry, R.J., Gordon, E., Rennie, C., Michie, P.T., 1998. Decrement of the N1 auditory event-related potential with stimulus repetition: Habituation vs. refractoriness. Int. J. Psychophysiol. 31, 51-68.

Courchesne, E., Hillyard, S.A., Galambos, R., 1975. Stimulus novelty, task relevance and the visual evoked potential in man. Electroen. Clin. Neuro. 39, 131-141.

Croft, R.J., Barry, R.J., 2000. Removal of ocular artifact from the EEG: a review. Clin.

Neurophysiol. 30, 5-19.

Croft, R.J., Chandler, J.S., Barry, R.J., Cooper, N.R., Clarke. A., 2005. EOG correction: A comparison of four methods. Psychophysiology 42, 16-24.

Crowley, K.E., Colrain, I.M., 2004. A Review of the evidence for P2 being an independent component process: age, sleep and modality. Clin. Neurophysiol. 115, 732-744.

Dien, J., 2010. The ERP PCA Toolkit: An open source program for advanced statistical analysis of event-related potential data. J. Neurosci. Meth. 187, 138-145.

Dien, J., 2012. Applying Principal Components Analysis to Event-Related Potentials: A tutorial. Dev. Neuropsychol. 37, 497-517. 
Donchin, E., Ritter, W., McCallum, W.C., 1978. Cognitive psychophysiology: The endogenous components of the ERP. In Callaway, E., Tueting, P., Koslow, H. (Eds.), Event-related potentials in man, New York: Academic Press, New York.

Edwards, D.C., 1974. Stimulus Intensity and Recency Contrasts and Orienting Response Strength. Psychophysiology 11, 543-547.

Edwards, D.C., 1975. Stimulus Intensity Reduction Following Habituation. Psychophysiology $12,12-14$.

Gillette, G.M., Skinner, R.D., Rasco, L.M., Fielstein, E.M., Davis, D.H., Pawelak, J.E., Freeman, T.W., Karson, C.N., Boop, F.A., Garcia-Rill, E., 1997. Combat Veterans with Posttraumatic Stress Disorder Exhibit Decreased Habituation of the P1 Midlatency Auditory Evoked Potential. Life Sciences 61, 1421-1434.

Howell, D., 1997. Statistical methods for psychology (6th ed.). Pacific Grove, CA: Thompson Wadsworth.

Iacono, W.G., Lykken, D.T., 1983. The Effects of Instructions on Electrodermal Habituation. Psychophysiology 20, 71-80.

Jackson, J.C., 1974. Amplitude and Habituation of the Orienting Reflex as a Function of Stimulus Intensity. Psychophysiology 11, 647-659.

Kaiser, J., Barry, R.J., Beauvale, A., 2001. Evoked cardiac response correlates of cognitive processing and dimensions of personality: Eysenck's concept of psychoticism revisited. Person. Individ. Diff. 30, 657-668.

Kayser, J., Tenke, C.E., 2003. Optimizing PCA methodology for ERP component identification and measurement: theoretical rationale and empirical evaluation. Clin. Neurophysiol. 114, 2307-2325.

Lacey, B.C., Lacey, J.I., 1980. Cognitive Modulation of Time-Dependent Primary Bradycardia. Psychophysiology 17, 209-221.

Lawrence, C.A., Barry, R.J., 2009. ERPs and the evoked cardiac response to auditory stimuli: 
Intensity and cognitive load effects. Acta Neurobiol. Exp. (War), 69, 552-559.

Lawrence, C.A., Barry, R.J., 2010. Cognitive processing effects on auditory event-related potentials and the evoked cardiac response. Int. J. Psychophysiol. 78, 100-106.

Lorenzo-Seva, U., ten Berge, J.M.F., 2006. Tucker's Congruence Coefficient as a Meaningful Index of Factor Similarity. Methodology 2, 57-64.

Loveless, N.E., Sandford, A,J., 1974. Slow Potential Correlates of Preparatory Set. Bio. Psychol. $1,303-314$.

Maltzman, I., 1979. Orienting Reflexes and Significance: A Reply to O’Gorman. Psychophysiology 13, 274-282.

Maltzman, I., 1990. The OR and Significance. Pav. J. Bio. Sci. 25, 111-122.

MacDonald, B., Barry, R.J., 2014. Trial effects in single-trial ERP components and autonomic responses at very long ISIs. Int. J. Psychophysiol. 92, 99-112.

MacDonald, B., Barry, R.J., Bonfield, R,C., 2015. Trials and intensity effects in single-trial ERP components and autonomic responses in a dishabituation paradigm at very long ISIs. Int. J. Psychophysiol. 98, 394-412.

McCallum, W.C., Curry, S.H., Cooper, R., Pocock, P.V., Papakostopoulos, D., 1983. Brain Event-Related Potentials as Indicators of Early Selective Process in Auditory Target Localization. Psychophysiology 20, 1-17.

Näätänen, R., 1982. Processing Negativity: An Evoked-Potential Reflection of Selective Attention. Psychol. Bull. 92, 605-640.

Näätänen, R., 1988. Implications of ERP Data for Psychological Theories of Attention. Bio. Psychol. 26, 117-163.

Näätänen, R., Picton, T., 1987. The N1 wave of the human electric and magnetic response to sound: A review and an analysis of the component structure. Psychophysiology 24, 375-425. Nieuwenhuis, S., Forstmann, B.U., Wagenmakers, E.J., 2011. Erroneous analyses of interactions in neuroscience: a problem of significance. Nat. Neurosci. 14, 1105-1107. 
O’Brien, R.G., Kaiser, M.K., 1985. MANOVA method for analyzing repeated measures designs: an extensive primer. Psychol. Bull. 97, 316-333.

O’Gorman, J.G., Mangan. G.L., Gowen, J., 1970. Selective habituation of the galvanic skin conductance component of the orienting reaction to an auditory stimulus. Psychophysiology 6, 716-721.

O’Gorman, J.G., 1979. The Orienting Reflex: Novelty or Significance. Psychophysiology 16, 253-262.

Picton, T.W., Hillyard, S.A., 1974. Human auditory evoked potentials. II: effects of attention. Electroen. Clin. Neuro. 36, 191-199.

Pratt, H., Starr, A., Michalewski, H.J., Bleich, N., Mittelman, N., 2008. The auditory $\mathrm{P}_{50}$ component to onset and offset of sound. Clin. Neurophysiol. 119, 376-387.

Pritchard, W.S., 1981. Psychophysiology of P300. Psychol. Bull. 89, 506-540.

Rankin, C.N., Abrams,T., Barry, R.J., Bhatnagar, S., Clayton, D.F., Colombo, J., Coppola, G., Geyer, M.A., Glanzman, D.L., Marsland, S., McSweeney, F.K., Wilson, D.A., Wu, C., Thompson, R.F., 2009. Habituation revisited: An updated and revised description of the behavioral characteristics of habituation. Neurobiol. Learn. Mem. 92, 135-138.

Raskin, D.C., Kotses, H., Bever, J., 1969. Autonomic Indicators of Orienting and Defensive Reflexes. J. Expt. Psychol. 80, 423-433.

Ritter, W., Vaughan, H.G., Costa, L.D., 1968. Orienting and Habituation to Auditory Stimuli: A Study of Short Term Changes in Average Evoked Responses. Electroen. Clin. Neuro. 25, 550-556.

Rohrbaugh, J.W., Syndulko, K., Lindsley, D.B., 1978. Cortical Slow Negative Waves Following Non-Paired Stimuli: Effects of Task Factors. Electroen. Clin. Neuro. 45, 551-567.

Rohrbaugh, J.W., Newlin, D.B., Varner, J.L., Ellingson, R.J., 1984. Bilateral Distribution of the O Wave. Ann. NY. Acad. Sci. 425, 267-270.

Romero, R., Polich, J., 1996. P3(00) Habituation from Auditory and Visual Stimuli. Physiol. 
Behav. 59, 517-522.

Roth, W.T., 1973. Auditory Evoked Responses to Unpredictable Stimuli. Psychophysiology 10, 125-138.

Rushby, J.A., Barry, R.J. 2009. Single-trial event-related potentials to significant stimuli. Int. J. Psychophysiol. 74, 120-131.

Rushby, J.A., Barry, R.J., Doherty, R.J., 2005. Separation of the components of the late positive complex in an ERP dishabituation paradigm. Clin.Neurophysiol.116, 2363-2380.

Sokolov, E.N., 1960. Neuronal models and the orienting reflex. In M. A. Brazier, M.A.B. (Ed.), The central nervous system and behavior. Macey, New York: pp. 187-276.

Sokolov, E.N., 1963a. Higher nervous functions: the OR. Ann. Rev. Physiol. 25, 545-580.

Sokolov, E.N., 1963b. Perception and the conditioned reflex. Pergamon, Oxford.

Squires, N., Squires, K., Hillyard, S., 1975. Two varieties of long-latency positive waves evoked by unpredictable auditory stimuli in man. Electroen. Clin. Neuro. 38, 387-401.

Steiner, G.Z., Barry, R.J., 2011. Pupillary responses and event-related potentials as indices of the orienting reflex. Psychophysiol. 48, 1648-1655.

Steiner, G.Z., Barry, R.J., 2014. Mechanism of dishabituation. Front. Integr. Neurosci.8:14.Doi: 10.3389/fnint.2014.00014.

Steiner, G.Z., Barry, R.J., De Blasio, F.M., 2014. ERPs in long and short ISI dishabituation tasks: A comparison using PCA. Int. J. Psychophysiol. 94, 120-261.

Sutton, S., Ruchkin, D.S., 1984. The Late Positive Complex Advances and New Problems. Ann. NY. Acad. Sci. 425, 1-23.

Tabachnick, B.G., Fidell, L.S., 1989. Using multivariate statistics. Harper Collins, NY.

Thompson, R.T., Spencer, W.A., 1966. Habituation: A model Phenomenon for the Study of Neuronal Substrates of Behavior. Psychol. Rev. 73, 16-43.

Tremayne, P., Barry, R.J., 1990. Repression of Anxiety and its Effects on Psychological Responses to Stimuli in Competitive Gymnasts. J. Exercise Sport Psychol. 12, 327-352. 
Tremayne, P., Barry, R.J., 2001. Elite pistol shooters: physiological pattern of best vs. worst shots. Int. J. Psychophysiol. 41, 19-29.

Vaughan, H.G., Ritter, W., 1970. The sources of auditory evoked responses recorded from the human scalp. Electroen. Clin. Neuro. 28, 360-367.

Velden, M., Wölk, C., 1987. Depicting cardiac activity over real time: a proposal for standardization. J. Physiol. 1, 173-175.

Woods, D.L., Courchesne, E., Hillyard, S.A., Galambos, R., 1980. Recovery cycles of eventrelated potentials in multiple detection tasks. Electroen. Clin. Neuro. 50, 335-347.

World Medical Organization. 1996. Declaration of Helsinki. British Medical Journal 13, 14481449.

Zimmer, H., Demmel, R., 2000. Habituation and laterality of orienting process as reflected by slow negative waves. Bio. Psychol. 53, 161-176.

Zimmer, H., 2006. Habituation of the orienting response as reflected by the skin conductance response and by endogenous event-related brain potentials. Int. J. Psychophysiol. 60, 4458.

Zimny, G.H., Schwabe, L.W., 1966. Stimulus change and habituation of the orienting response. Psychophysiology 2, 103-115. 


\section{Figure legends}

Figure 1. A schematic of PPT. Sequential and parallel processing of indifferent stimulus information leads to the generation of the OR from the interaction of novelty and stimulus magnitude processing. The smaller, lighter dashed rectangles indicate measures indexing the processing of each of the modules. The larger, bolder dashed line represents the moderation of the modules by Maltzman's cortical set. Physiological responses: HR decel, Heart rate deceleration; CVD, cephalic vasodilation; Resp, respiratory pause; EEG, EEG alpha desynchronisation; PVC, peripheral vasoconstriction; GSR, galvanic skin response (now SCR); HR accel, heart rate acceleration.

Figure 2. The square-root transformed phasic SCR as a function of trials and levels of Significance: NC (No Count) and C (Count). SE bars indicate the trial to trial variation, and the linear regression line and Coefficient of Determination for the first 10 trials are included.

Figure 3. Panel A. Mean phasic HR response for NC (No Count), C (Count), and estimated ECR2 (Count - No Count) relative to the pre-stimulus level across time. Vertical scale: change in beats per minute; horizontal scale: s. Panel B. Maximum HR deceleration over the 12 trials for both levels of Significance: NC (No Count) and C (Count). Vertical scale:

Maximum HR deceleration in beats per minute; horizontal scale: trials. Panel C. Maximum HR acceleration over the 12 trials for levels of Significance NC: (No Count) and C (Count). Vertical scale: Maximum HR acceleration in beats per minute; horizontal scale: trials. Time point variation is indicated by SE bars. Linear regression line and Coefficient of Determination for the first 10 trials are included.

Figure 4. Respiratory Pause as a function of trials and levels of Significance: NC (No Count) and C (Count), with SE bars. The linear regression line and Coefficient of Determination over the first 10 trials are also indicated.

Figure 5. The left panel shows the grand mean ERPs across subjects, levels of Significance: NC (No Count) and C (Count), and across 12 trials at each of the midline sites, with well-defined 
components labelled at $\mathrm{Cz}$. The right panel depicts the corresponding virtual ERPs derived from the sum of the first ten virtual PCA components/subcomponents over Significance and across 12 trials. The actual and virtual ERPs correspond very closely. Vertical scale: $\mu \mathrm{V}$; horizontal scale: $\mathrm{ms}$.

Figure 6. Rescaled factor loadings for the 10 PCA-derived ERPs. Each of the 10 factor loading peaks corresponds to the topographic grand mean headmap of that component along with its peak latency. Vertical scale: $\mu \mathrm{V}$; horizontal scale: ms. See web for colour version.

Figure 7. The headmaps of 10 PCA-derived ERPs from 9 sites over levels of Significance: NC (No Count) and C (Count) are shown as a function of focal trials and overall topography. Maximum averages at the midline for each component are marked by a grey ellipse. See web for colour version.

Figure 8. Pooled maximum amplitudes of the 10 PCA-derived ERPs at the sagittal regions over levels of Significance: NC (No Count) and C (Count) and trials. Time point variation is indicated by SE bars. Coefficient of Determination for the first 10 trials is included.

Figure 9. Topographic headmaps of PCA components from the present study and MacDonald and Barry (2014) are depicted. Latencies, \% component variance, factor ranking, and Congruence coefficient are presented for comparison. See web for colour version. 